\title{
Atomistic investigation of the effects of temperature and surface roughness on diffusion bonding between $\mathrm{Cu}$ and $\mathrm{Al}$
}

\author{
Shangda Chen ${ }^{\mathrm{a}, \mathrm{b}, *}$, Fujiu Ke ${ }^{\mathrm{a}, \mathrm{b}}$, Min Zhou ${ }^{\mathrm{c}}$, Yilong Bai ${ }^{\mathrm{b}}$ \\ ${ }^{a}$ Department of Physics, Beihang University, Beijing 100083, China \\ ${ }^{\mathrm{b}}$ State Key Laboratory of Non-linear Mechanics (LNM), Institute of Mechanics, Chinese Academy of Sciences, Beijing 100080, China \\ ${ }^{\mathrm{c}}$ The George W. Woodruff School of Mechanical Engineering, Georgia Institute of Technology, Atlanta, GA 30332-0405, USA
}

Received 10 June 2006; received in revised form 28 December 2006; accepted 29 December 2006

Available online 7 March 2007

\begin{abstract}
Molecular dynamics (MD) simulations are carried out to analyze the diffusion bonding at $\mathrm{Cu} / \mathrm{Al}$ interfaces. The results indicate that the thickness of the interfacial layer is temperature-dependent, with higher temperatures yielding larger thicknesses. At temperatures below $750 \mathrm{~K}$, the interface thickness is found to increase in a stepwise manner as a function of time. At temperatures above $750 \mathrm{~K}$, the thickness increases rapidly and smoothly. When surface roughness is present, the bonding process consists of three stages. In the first stage, surfaces deform under stress, resulting in increased contact areas. The second stage involves significant plastic deformation at the interface as temperature increases, resulting in the disappearance of interstices and full contact of the surface pair. The last stage entails the diffusion of atoms under constant temperature. The bonded specimens show tensile strengths reaching $88 \%$ of the ideal $\mathrm{Cu} / \mathrm{Al}$ contact strength.
\end{abstract}

(C) 2007 Acta Materialia Inc. Published by Elsevier Ltd. All rights reserved.

Keywords: Diffusion bonding; Molecular dynamics; Temperature effect; Tensile strength

\section{Introduction}

Diffusion bonding is a solid-state welding process that allows contacting surfaces to be joined under pressure and at elevated temperatures with minimum macroscopic deformation [1]. Almost all materials with compatible chemical and metallurgical properties can be diffusionbonded [2]. This welding process has an inherent advantage over conventional welding since it does not involve the formation of unexpected phases at the bond interface which can occur in some advanced materials [2-6]. Theoretical and experimental studies have been carried out on diffusion bonding, primarily at continuum scales [1-8]. In contrast, analyses at atomic scale have scarcely been carried out.

\footnotetext{
* Corresponding author. Address: State Key Laboratory of Non-linear Mechanics (LNM), Institute of Mechanics, Chinese Academy of Sciences, Beijing 100080, China.

E-mail address: chensd@Inm.imech.ac.cn (S. Chen).
}

Molecular dynamics (MD) simulations has become one of the most widely used tools in nanomechanics primarily because it is not limited by uncertainties in sample preparation and test condition and can be used to analyzed a range of issues concerning mechanical behavior at the nanoscale. Weissmann et al. [9] used MD simulations to show that interfacial amorphization clearly develops at higher temperatures in a $\mathrm{Co}-\mathrm{Zr}$ system. Chen et al. [10] calculated the interfacial energy of an face-centered cubic (fcc)/ body-centered cubic interface in $\mathrm{Ni}-\mathrm{Cr}$ alloys. Cherne et al. [11] investigated the amorphization of an $\mathrm{Ni}-\mathrm{Zr}$ system. The microstructures of a $\mathrm{Cu} / \mathrm{Ta}$ interface [12] and an $\mathrm{SiO}_{2} / \mathrm{Si}$ interface [13] have also been analyzed by means of MD simulations. The conditions analyzed in these papers are significantly different from the conditions of actual diffusion bonding processes which involve combined high temperature and high pressure. As a result, interfacial diffusion does not occur and no transition regions are seen. Since temperature and pressure play an important roles, 
MD simulations accounting for such conditions can provide significant insight which may not be obtainable by other means. Another factor motivating MD analyses of diffusion bonding processes is the lack of quantification of the effects of surface roughness, which also plays an important role. MD simulations also offer the advantage of extensive parametric studies, potentially avoiding the need of long and expensive experiments. Recently, Chen et al. [14] reported an MD study of the pressure effect in diffusion bonding between $\mathrm{Cu}$ and $\mathrm{Ag}$, and Liu et al. [15] investigated the cooling effect in diffusion bonding between $\mathrm{Cu}$ and $\mathrm{Al}$. In the present paper, we consider the coupled temperature-roughness effects in the diffusion bonding of a $\mathrm{Cu}-\mathrm{Al}$ material pair.

\section{Simulation procedure}

Interatomic potentials play a very important role in MD simulations. Considerable progress has been made in the development of empirical and semi-empirical many-body potentials. Well-established embedded atomic method (EAM) potentials [16] have been successfully used in analyzing elastic properties, defect formation energy and fracture mechanisms of various close-packed bulk metals. Here, the modified EAM model developed by Johnson $[17,18]$ for alloys is adopted. This potential predicts heats of solution for the materials involved that is consistent with what is measured from experiments.

As shown in Fig. 1, the system analyzed consists of a monocrystal copper slab (top) and a monocrystal aluminum slab (bottom). The contact surfaces of $\mathrm{Cu}$ and $\mathrm{Al}$ are both (100) planes. The total numbers of the $\mathrm{Cu}$ and $\mathrm{Al}$ atoms in the model are 52,488 and 46,080, respectively. A parallel algorithm is used. Periodic boundary conditions are implemented in the two transverse directions. Three layers of atoms at the bottom of the Al slab and two layers at the top of the $\mathrm{Cu}$ slab serve as boundary atoms for the purpose of load or displacement application. The initial thermal velocities of atoms are assumed to follow the Maxwellian distribution. The Newton's equation of motion for the atoms is numerically integrated using the leap-frog algorithm [19] with a fixed time step of 2 fs. The external transverse pressure is maintained at atmospheric level, while the vertical pressure is $20 \mathrm{MPa}$. The structures are first equilibrated at $1 \mathrm{~K}$ for $10 \mathrm{ps}$ and then heated up to a desired temperature (up to $750 \mathrm{~K}$ ) at a rate of $5 \times 10^{13} \mathrm{~K} \mathrm{~s}^{-1}$. Subsequently, the temperature is kept constant at the desired value through the scaling of atomic momenta. To achieve sufficient interfacial diffusion, all calculations are carried out for $600 \mathrm{ps}$ at the desired temperature.

\section{Results and discussions}

\subsection{Effect of temperature}

Atoms on either side of the interface can diffuse into the opposite side only if temperature is sufficiently high. Necessary levels of temperatures are usually between $0.6-0.8 T_{\mathrm{m}}$ (where $T_{\mathrm{m}}$ represents the melting points of the materials involved). Since the melting point of $\mathrm{Al}$ is $933 \mathrm{~K}$ and that for $\mathrm{Cu}$ is $1083 \mathrm{~K}$, the temperature levels of $600,650,700$ and $750 \mathrm{~K}$ are considered here.

Fig. 1 shows the configuration of a cross-section of the structure after $600 \mathrm{ps}$ of diffusion at different temperatures. At $600 \mathrm{~K}$, only a small number of $\mathrm{Cu}$ atoms have diffused into the $\mathrm{Al}$ side and there is no obvious structural change since both sides retain their initial fcc lattice structures (see Fig. 1a). At $650 \mathrm{~K}$ (Fig. 1b), more $\mathrm{Cu}$ atoms have diffused into the $\mathrm{Al}$ side. When the temperature is higher than $650 \mathrm{~K}$, more significant diffusion of $\mathrm{Cu}$ atoms into $\mathrm{Al}$ is seen, forming an Al-rich interfacial region. This interfacial region and the rest of the Al block exhibit an amorphous structural order when the temperature is at or above $650 \mathrm{~K}$ (Fig. 1b-d). This observation agrees well with the observation by Weissmann et al. [9] of a similar disordered interface in a $\mathrm{Co}-\mathrm{Zr}$ system at high temperatures. Fig. 1 also shows that the diffusion is primarily one way, from the $\mathrm{Cu}$ side into the $\mathrm{Al}$ side. This is because $\mathrm{Cu}$ atoms have a smaller radius $(2.556 \AA)$ than that of $\mathrm{Al}$ atoms $(2.886 \AA)$. Obviously, it is easier for smaller atoms to diffuse into a region of larger atoms [20]. On the other hand, the melting

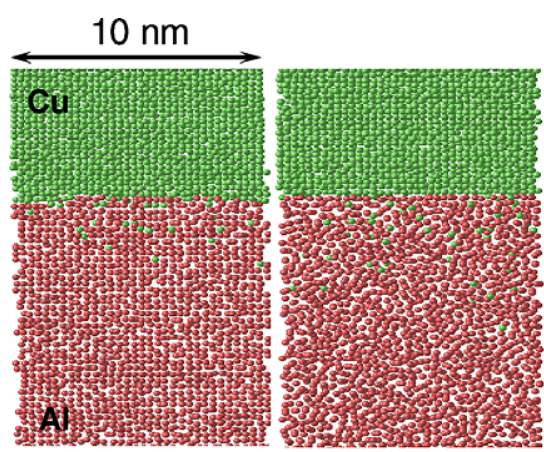

(a) $600 \mathrm{~K}$ (b) $650 \mathrm{~K}$

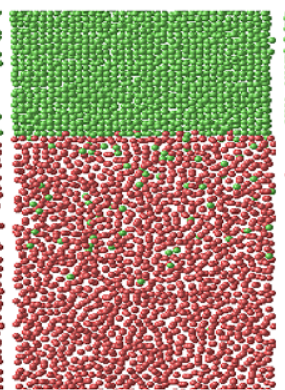

(c) $700 \mathrm{~K}$

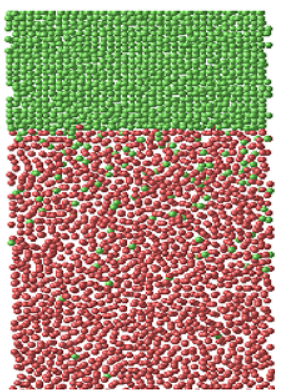

(d) $750 \mathrm{~K}$

Fig. 1. Configurations of a cross-section at (a) $600 \mathrm{~K}$, (b) $650 \mathrm{~K}$, (c) $700 \mathrm{~K}$ and (d) $750 \mathrm{~K}$ after $600 \mathrm{ps}$. Only atoms near the interface are shown. Cu atoms are green and $\mathrm{Al}$ atoms are red. (For interpretation of the references to colour in this figure legend, the reader is referred to the conversion of this article.) 
point of $\mathrm{Cu}$ is higher than that of $\mathrm{Al}$, making it harder to break the bonds between $\mathrm{Cu}$ atoms than those between $\mathrm{Al}$ atoms, making it more difficult for $\mathrm{Al}$ atoms to diffuse into the $\mathrm{Cu}$ lattice. In contrast, the bonds in $\mathrm{Al}$ are weaker and vacancies form more easily. All three factors favor the diffusion of $\mathrm{Cu}$ atoms into $\mathrm{Al}$, and not the other way around.

Fig. 2 shows the concentrations of $\mathrm{Cu}$ and $\mathrm{Al}$ atoms along the vertical direction for the four cases in Fig. 1. The region spanning both sides of the interface where the concentration of the solute atoms is over $5 \%$ is defined as the interfacial region. The size of this region can be determined from the concentration profiles. At $600 \mathrm{~K}$, the thickness is approximately $6 \AA$ (Fig. 2a), indicating very little diffusion across the interface. The thickness increases as temperature increases, with the values being 11, 19 and $30 \AA$ at 650,700 and $750 \mathrm{~K}$, respectively.

Fig. 3 shows the thickness of the interfacial region as a function of time at different temperatures. At $600 \mathrm{~K}$, the thickness fluctuates between 0 and $4 \AA$ (smaller than two atomic layers) in the initial stage. After about $400 \mathrm{ps}$, the thickness reaches approximately $6 \AA$ and does not show further increase except for minor fluctuations. At $650 \mathrm{~K}$, the thickness shows stepwise increases to $11 \AA$ by about $550 \mathrm{ps}$ and shows no further increase thereafter. The profile for $700 \mathrm{~K}$ is similar to that for $650 \mathrm{~K}$, except that the maximum thickness value is higher $(18 \AA)$. At $750 \mathrm{~K}$, the thickness increases rapidly and continuously without saturation over the duration of the calculation.

\subsection{Effect of surface roughness}

Experiments have shown that the roughness of contact surfaces has a significant impact on the bonding process [21]. Some theoretical analyses have been carried out to address this issue at continuum scales [22-24]. In this section, we consider three different cases at the atomic scale:

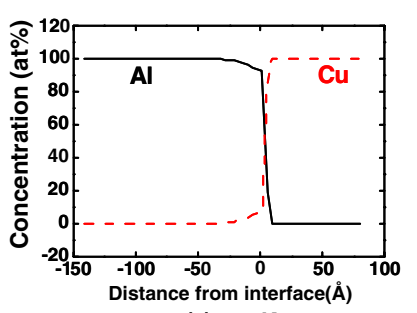

(a) $600 \mathrm{~K}$

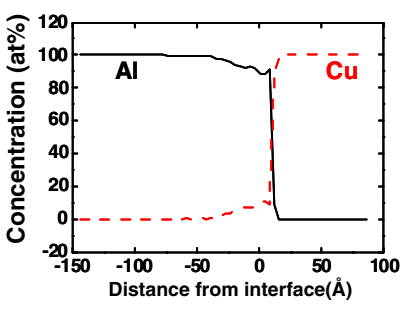

(c) $700 \mathrm{~K}$

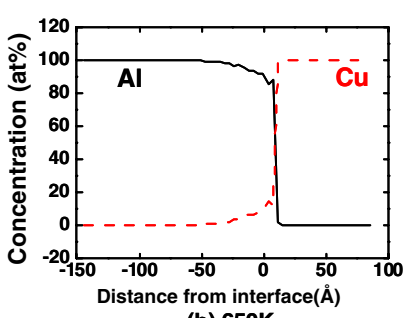

(b) $650 \mathrm{~K}$

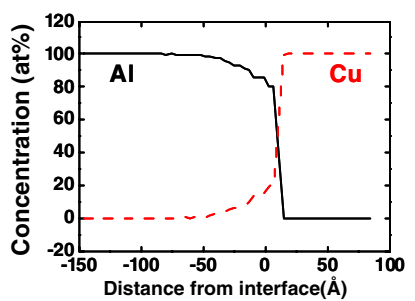

(d) $750 \mathrm{~K}$
Fig. 2. Concentrations of $\mathrm{Cu}$ and $\mathrm{Al}$ atoms along the vertical direction at (a) $600 \mathrm{~K}$, (b) $650 \mathrm{~K}$, (c) $700 \mathrm{~K}$ and (d) $750 \mathrm{~K}$ after $600 \mathrm{ps}$.

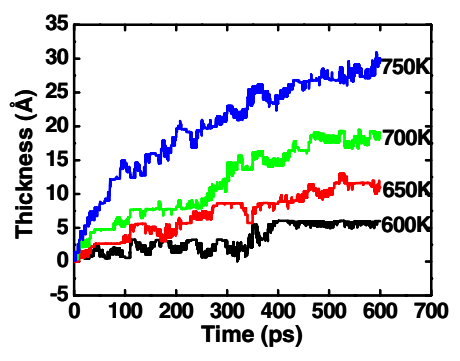

Fig. 3. Thickness of the interfacial region as a function of time at different temperatures.

(i) smooth $\mathrm{Cu}$ surface and rough $\mathrm{Al}$ surface with two protuberances of a height of 4 lattice constants for $\mathrm{Al}$;

(ii) smooth $\mathrm{Al}$ surface and rough $\mathrm{Cu}$ surface with two protuberances of a height of 4 lattice constants for $\mathrm{Cu}$; and

(iii) both surfaces are rough. In all three cases, the highest temperature is $700 \mathrm{~K}$ and the applied stress in the $z$ direction is $20 \mathrm{MPa}$.

Fig. 4 shows the configurations of a cross-section at different temperatures for case (i). Obviously, the protuberances on the Al surface undergo significant deformation under stress, even at $200 \mathrm{~K}$ (Fig. 4b). However, interstices remain between the two sides. At $300 \mathrm{~K}$, the protuberances are completely flattened and fully intimate contact is achieved. It should be noted that the heights of the protuberances in the simulations here are 1-2 orders of magnitude lower than those found in many laboratory diffusion bonding processes. This translates into a very large number of interstices between the surfaces at the macroscopic scale that is analyzed in Refs. [21,22]. Because Al is softer than $\mathrm{Cu}$, more pronounced deformation is seen in $\mathrm{Al}$. From Fig. 4c, it can also be seen that a layer of $\mathrm{Al}$ close to the interface becomes amorphous. The picture at $700 \mathrm{~K}$ is similar to that at $300 \mathrm{~K}$, with no obvious diffusion of atoms across the interface in either direction.

Fig. 5 shows the same cross-section for case (ii). The smooth Al surface undergoes significant deformation under the applied stress when the temperature is increased to $200 \mathrm{~K}$. Some of the $\mathrm{Al}$ atoms fill in the interspaces of the $\mathrm{Cu}$ surface (Fig. 5b). This process intensifies as temperature increases (Fig. 5c). At $400 \mathrm{~K}$, the interspaces on the $\mathrm{Cu}$ surface are fully filled. The image at 700 is similar to that at $400 \mathrm{~K}$, with no obvious diffusion between the two sides.

Fig. 6 shows the results for case (iii). The tops of the Al protuberances are flattened by the applied stress even before the temperature is increased. At $200 \mathrm{~K}$, the $\mathrm{Al}$ side shows significant deformation, similar to that seen in previous cases. Some $\mathrm{Al}$ atoms fill in the interspaces of the $\mathrm{Cu}$ surface (Fig. 6b) and the protuberances on the $\mathrm{Cu}$ side show slight deformation. As the temperature increases, more $\mathrm{Al}$ atoms move into interspaces on the $\mathrm{Cu}$ surface (Fig. 6c). At $400 \mathrm{~K}$, the interspaces are completely filled. 


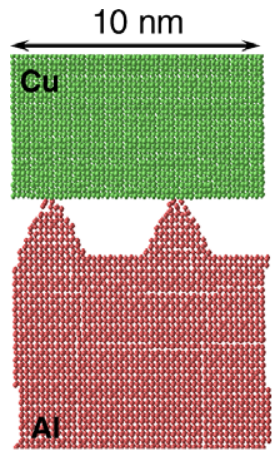

(a) Initial state

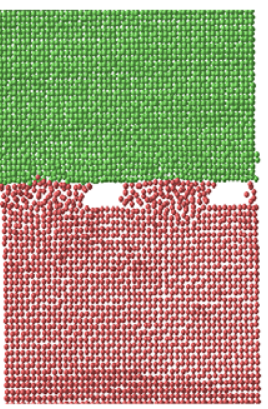

(b) $200 \mathrm{~K}$

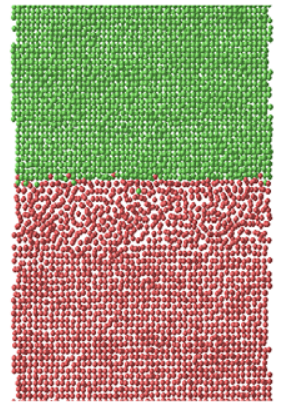

(c) $300 \mathrm{~K}$

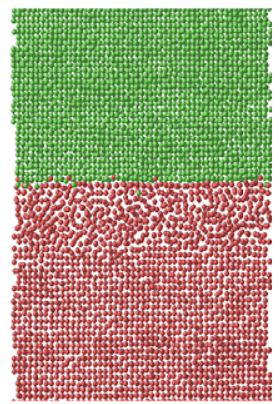

(d) $700 \mathrm{~K}$

Fig. 4. Deformed configurations of a cross-section at different temperatures for case (i) (the stress is kept at $20 \mathrm{MPa}$ ).

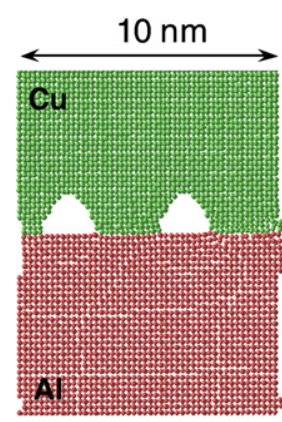

(a) $1 \mathrm{~K}$

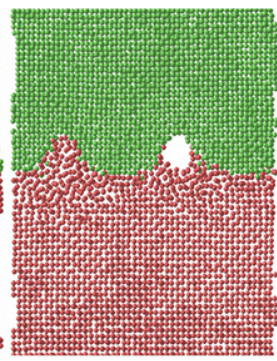

(b) $200 \mathrm{~K}$

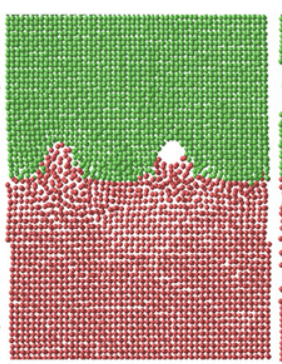

(c) $300 \mathrm{~K}$

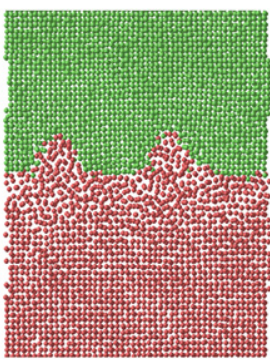

(d) $400 \mathrm{~K}$

Fig. 5. Deformed configurations of a cross-section at different temperatures during heating for case (ii) (the stress is kept at $20 \mathrm{MPa}$ ).

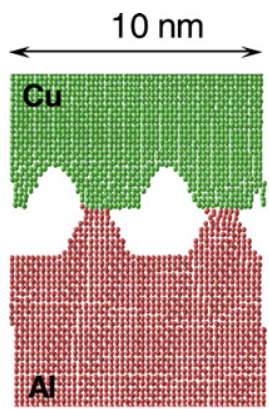

(a) $1 \mathrm{~K}$

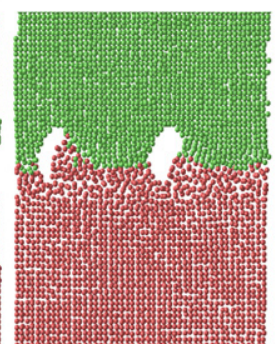

(b) $200 \mathrm{~K}$

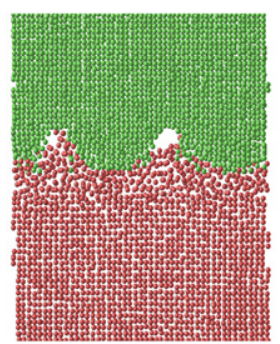

(c) $300 \mathrm{~K}$

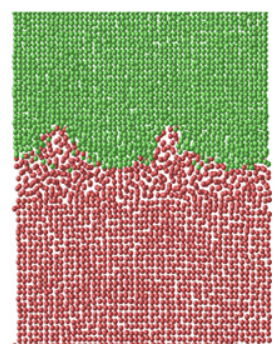

(d) $400 \mathrm{~K}$

Fig. 6. Deformed configurations of a cross-section at different temperatures for case (iii) (the stress is kept at $20 \mathrm{MPa}$ ).

The results in Figs. 4-6 show that deformation primarily occurs in the $\mathrm{Al}$, regardless of the configuration of the $\mathrm{Cu}$ surface. This is because $\mathrm{Cu}$ has greater strength and a higher melting point.

Fig. 7 shows the same cross-section as that in Figs. 4-6 after $600 \mathrm{ps}$ at $700 \mathrm{~K}$ for cases (i) and (ii). As pointed out previously, the rough $\mathrm{Al}$ surface is flattened during heating before diffusion (Fig. 4d). Consequently, the diffusion pattern in Fig. 7a at $600 \mathrm{ps}$ is similar to that in the case with perfectly smooth surfaces (Fig. 1). The diffusion pattern in Fig. $7 \mathrm{~b}$ is very different from those in Figs. 1 and 7a. This difference arises because $\mathrm{Al}$ atoms have previously filled the interspaces during heating and the contact profile is similar to those in cases (ii) and (iii) when the $\mathrm{Cu}$ surface is rough before diffusion (Figs. 5d and 6d). Specifically, after 600 ps the contact profile is very similar to the initial profile of the $\mathrm{Cu}$ surface, except that it has become flatter (Fig. 7b).

The three sets of results show that the diffusion bonding process can be divided into three stages. In the first stage, the rough surface deforms under stress before heating, causing the contact area to increase. In the second stage, the softer $(\mathrm{Al})$ surface undergoes significant deformation as temperature increases, causing the interstices to disappear and leading to fully intimate contact of the surfaces. The last stage is the diffusion of atoms at constant temperature. In Derby's theoretical model [22,23], possible diffusion bonding mechanisms were identified as: (i) plastic deformation of surface asperities; (ii) power-law creep deformation of the surface; (iii) diffusion of matter from interfacial void surfaces to growing necks; and (iv) diffu- 


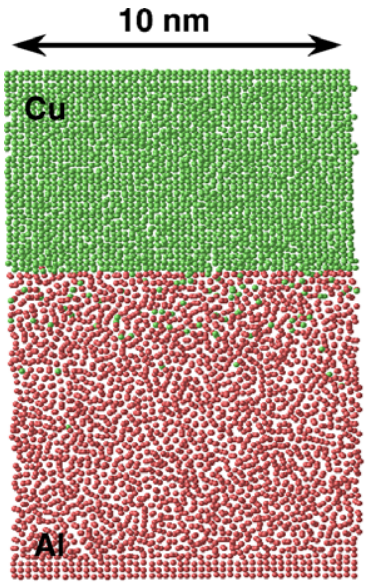

(a) smooth Cu surface

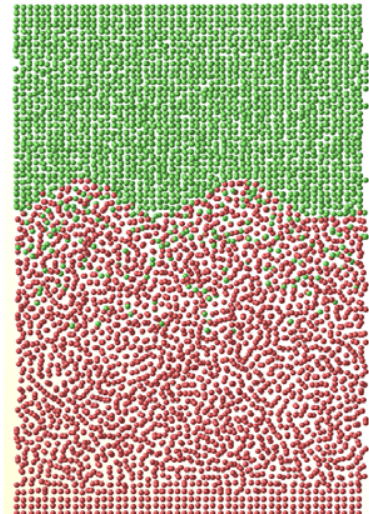

(b) rough $\mathrm{Cu}$ surface

Fig. 7. Configurations of a cross-section after $600 \mathrm{ps}$ at $700 \mathrm{~K}$; (a) case (i), (b) case (ii).

sion of matter from bonded regions on the interface to growing necks. The MD results obtained here present a very similar understanding and therefore add credence to the continuum model. The only difference is that no interstices remain before diffusion in the MD simulations and therefore there is no diffusion of matter from interfacial voids to growing necks.

\subsection{Tensile deformation}

In order to examine and assess the mechanical properties of the diffusion-bonded $\mathrm{Cu} / \mathrm{Al}$ samples, tensile loading is applied at $300 \mathrm{~K}$ to the diffusion-bonded $\mathrm{Cu} / \mathrm{Al}$ pair in Fig. 1d which is obtained by bringing a perfect fcc Cu crystal and a perfect fcc Al crystal into contact and then allowing the structure to first equilibrate at $1 \mathrm{~K}$ for $10 \mathrm{ps}$, be heated up to $750 \mathrm{~K}$ at a rate of $5 \times 10^{13} \mathrm{~K} \mathrm{~s}^{-1}$, equilibrate at $750 \mathrm{~K}$ for $600 \mathrm{ps}$, and finally be cooled down to $300 \mathrm{~K}$ at a rate of $5 \times 10^{13} \mathrm{~K} \mathrm{~s}^{-1}$. For comparison purposes, the same tensile loading is also applied to monocrystal $\mathrm{Cu}$, monocrystal $\mathrm{Al}$, and a $\mathrm{Cu} / \mathrm{Al}$ pair with ideal contact (obtained by bringing a perfect fcc $\mathrm{Cu}$ crystal and a perfect fcc Al crystal into contact and then allowing the structure to equilibrate at $300 \mathrm{~K}$ for $10 \mathrm{ps}$ under atmospheric pressure). To effect the tensile deformation, the displacement of the boundary atoms is controlled by time steps. Each loading increment corresponds to a strain of $0.25 \%$ and is followed by a period of 8 ps of equilibration at constant strain. Although the strain rate for a loading step alone is approximately $3 \times 10^{8} \mathrm{~s}^{-1}$, which is several orders of magnitude higher than the rate in a typical tensile test, the equilibration periods following the load steps allow a steady state to be reached at the end of each increment. Therefore, the calculation here can be regarded as approximating quasistatic loading, as shown in a previous investigation [25].

Fig. 8 shows the nominal stress-strain curves for monocrystal $\mathrm{Cu}$ and $\mathrm{Al}, \mathrm{Cu} / \mathrm{Al}$ pair with ideal contact and diffu-

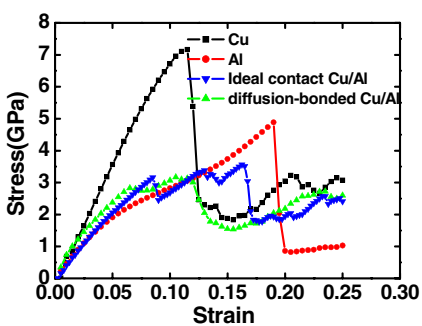

Fig. 8. Tensile stress-strain curves of monocrystal $\mathrm{Cu}$ and $\mathrm{Al}, \mathrm{Cu} / \mathrm{Al}$ pair with ideal contact and diffusion-bonded $\mathrm{Cu} / \mathrm{Al}$ pair.

sion-bonded $\mathrm{Cu} / \mathrm{Al}$ pair. It can be seen that the stress reaches a maximum of $7.2 \mathrm{GPa}$ at a strain of $11.5 \%$ for monocrystal $\mathrm{Cu}$. Beyond the strain of $11.5 \%$, the stress drops precipitously to $2.5 \mathrm{GPa}$ and plastic flow occurs at stresses of around $2.5 \mathrm{GPa}$. The curve for monocrystal $\mathrm{Al}$ has features similar to those for monocrystal $\mathrm{Cu}$, with a maximum stress of $4.9 \mathrm{GPa}$ at a strain of $19.5 \%$. When the strain exceeds $19.5 \%$, the stress drops precipitously to $0.8 \mathrm{GPa}$ and plastic flow occurs at stresses around $1 \mathrm{GPa}$. The curve for the ideal-contact $\mathrm{Cu} / \mathrm{Al}$ pair is different from those for monocrystal $\mathrm{Cu}$ and $\mathrm{Al}$. A sudden drop of stress appears first when the strain reaches $8.5 \%$, followed by a second drop at a strain of $13 \%$. The stress reaches a maximum of $3.6 \mathrm{GPa}$ at a strain of $16 \%$. When the strain is over $16 \%$, stress drops from 3.6 to $1.6 \mathrm{GPa}$ and the sample shows plastic flow. The flow stress is about $2 \mathrm{GPa}$. Finally, the case of the diffusion-bonded $\mathrm{Cu} / \mathrm{Al}$ pair is similar to that of the ideal-contact $\mathrm{Cu} / \mathrm{Al}$ pair, with no obvious sudden stress drop as strain increases. The stress-strain curve is flatter than that of the ideal-contact case. When the strain is over $6.5 \%$, the stress shows a small drop and then increases as strain increases. The curve yields a tensile strength of $3.2 \mathrm{GPa}$, which occurs at a strain of $10.5 \%$. The diffusion-bonded $\mathrm{Cu} / \mathrm{Al}$ pair is quite strong, demonstrating a tensile strength that can reach $88 \%$ of that for the ideal-contact $\mathrm{Cu} / \mathrm{Al}$ case. The stress drops from 3.2 to $1.5 \mathrm{GPa}$ as the strain increases from 10.5 to $15 \%$, and the increase from $15 \%$ to $22.5 \%$ is very gradual due to the plastic flow.

We now turn our attention to the deformed structures inside the samples to gain a better insight into the observed mechanical behaviors. Fig. 9 shows the deformed configurations of monocrystal $\mathrm{Cu}$ at different strains. Atoms with normalized centrosymmetry values between 0.88 and 0.92 are colored red. These atoms are associated with dislocations. Other atoms not involved in defects are colored blue. No obvious change in structure is observed as the strain increases from $0 \%$ to $11.5 \%$, except for the elongation of the sample. The picture becomes very different at a strain of $12 \%$, when many slip bands (red atoms) appear on the side surfaces. The slip bands on the surfaces form an angle of $45^{\circ}$ relative to the loading axis (Fig. 9c and d). The formation of these slip bands results in the sudden drops of stress in the stress-strain curves discussed earlier. As the strain increases, more bands appear (Fig. 9d). The 


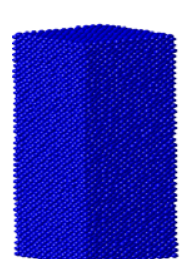

(a)

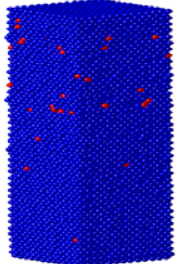

(b)

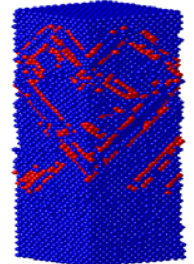

(c)

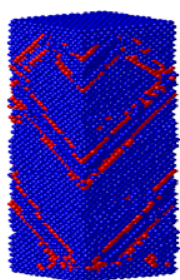

(d)

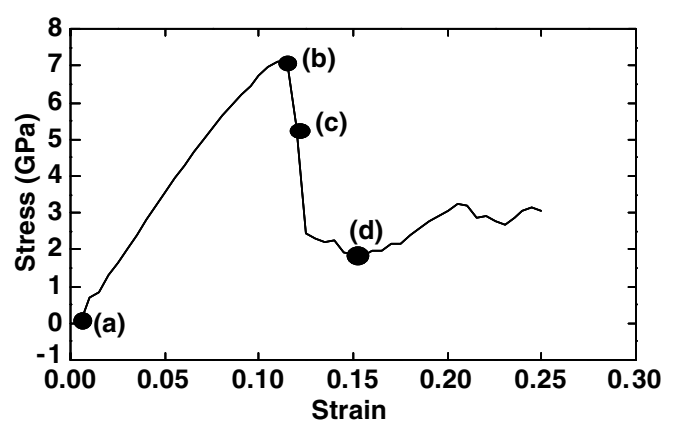

Fig. 9. Deformed configurations of monocrystal $\mathrm{Cu}$ at different levels of stain. Atoms with normalized centrosymmetry values between 0.88 and 0.92 are colored red, other atoms are blue. (For interpretation of the references to colour in this figure legend, the reader is referred to the conversion of this article.)

deformation of monocrystal $\mathrm{Al}$ is very similar to that of monocrystal $\mathrm{Cu}$, except that slips bands begin to appear at a strain of $19 \%$ instead of $12 \%$.

Fig. 10 shows deformed configurations of the ideal-contact $\mathrm{Cu} / \mathrm{Al}$ pair at different strains. In Fig. 10-(1), or the top row of images, $\mathrm{Cu}$ atoms are blue and $\mathrm{Al}$ atoms are red. In Fig. 10-(2), or the second row of images, only atoms with normalized centrosymmetry values between 0.86 and 0.92 are shown. Fig. 10a and b shows that there is no obvious dislocation activity in $\mathrm{Cu}$ before a strain of $8.5 \%$; however, active dislocations are seen in the Al half (Fig. 10-(2)a and b). At a strain of $9 \%$, a few slip bands appear on the side surfaces on the $\mathrm{Al}$ side and an $\mathrm{Al}$ layer adjacent to $\mathrm{Cu}$ becomes amorphous (Fig. 10-(1)b, not shown clearly). The appearance of slip bands on the $\mathrm{Al}$ side results in the sudden drop of stress at a strain of $8.5 \%$. Some of the slip bands disappear and new slip bands appear as strain increases (Fig. 10-(1)b and c). From Fig. 10-(2)b and c, it can be seen that some dislocations in the $\mathrm{Al}$ half disappear as strain increases. This process is accompanied by the emergence of dislocations in the $\mathrm{Cu}$ half. At strains above 16\% (Fig. 10d), slip bands appear on the $\mathrm{Cu}$ side (not shown clearly), resulting in another sudden drop in stress. Further deformation is associated primarily with the development of additional slip bands on the $\mathrm{Cu}$ side (not shown).

Fig. 11 shows deformed configurations of the diffusionbonded $\mathrm{Cu} / \mathrm{Al}$ pair at different strains. The results are similar to those for the ideal-contact case in the following ways. First, there are no obvious changes in $\mathrm{Cu}$ before a strain of $7 \%$ (Fig. 11-(1)a); however, some dislocations are seen in the Al half (Fig. 10-(2)a). The dislocations move to the $\mathrm{Al}$ surface (Fig. 10-(2)b), appearing as slip bands on the side surfaces. This process also involves the amorphization of a layer of $\mathrm{Al}$ immediately next to the interface (Fig. 11-(2)b, not clearly shown). The appearance of slip
(1)
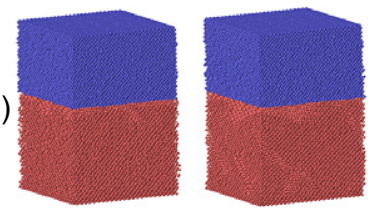

(2)

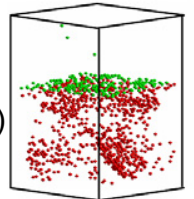

(a)

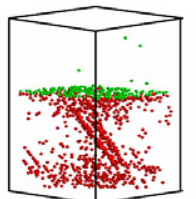

(b)
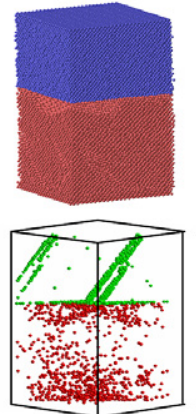

(c)
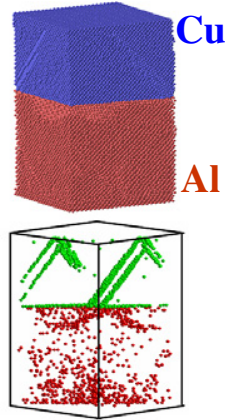

(d)

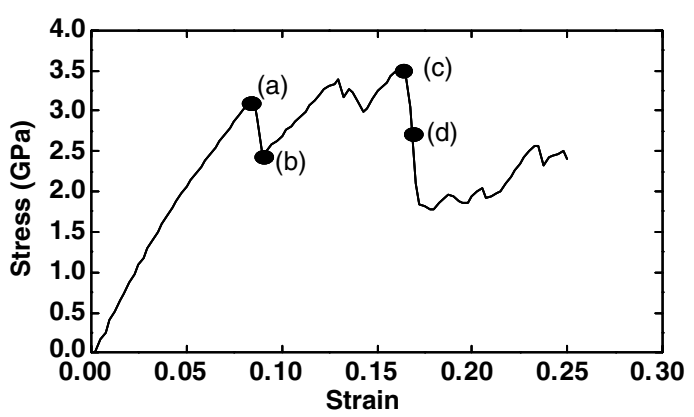

Fig. 10. Deformed configurations of ideal-contact $\mathrm{Cu} / \mathrm{Al}$ pair at different strain levels: (a) $8.5 \%$, (b) $9 \%$, (c) $16 \%$ and (d) $16.5 \%$. Only atoms with normalized centrosymmetry values between 0.86 and 0.92 are shown in (2).

(1)
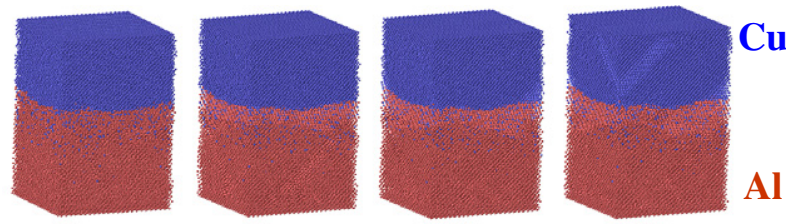

(2)

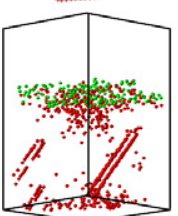

(a)

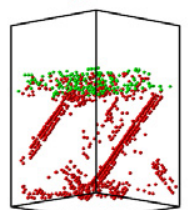

(b)

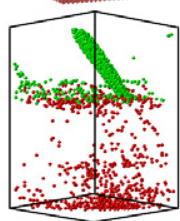

(c)

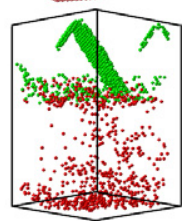

(d)

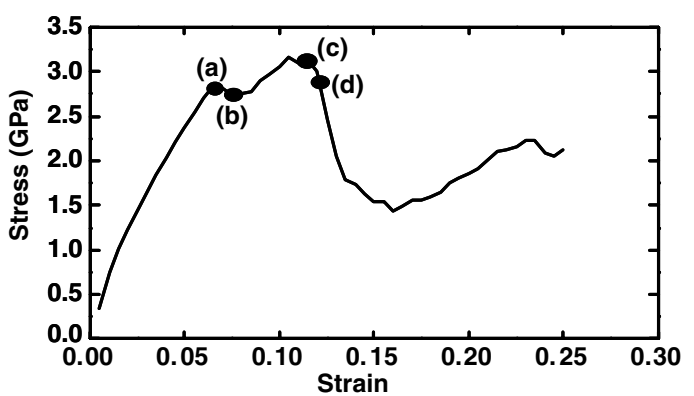

Fig. 11. Deformed configurations of diffusion-bonded $\mathrm{Cu} / \mathrm{Al}$ pair at different strain levels: (a) $6.5 \%$, (b) $7 \%$, (c) $10.5 \%$ and (d) $11 \%$. Only atoms with normalized centrosymmetry values between 0.86 and 0.92 are shown in (2). 
bands on the $\mathrm{Al}$ side and the amorphization cause the stress to decrease slightly, beginning at a strain of $6.5 \%$. The dislocations in $\mathrm{Al}$ do not propagate through the interface (Fig. 11-(2)b and c). Further deformation is associated with the disappearance of dislocations on the $\mathrm{Al}$ side and the emergence of dislocations on the $\mathrm{Cu}$ side (Fig. 11-(2)c and d). Phenomenologically, this leads to strain hardening, as seen in the stress-strain relation. When the strain is over $10.5 \%$, dislocations reach the side surface of the $\mathrm{Cu}$ half (Fig. 11-(2)d) and slip bands appear (Fig. 11-(1)d, not clearly visible), resulting in the second drop of stress.

To summarize, the stress-strain curves show that the tensile strengths of monocrystal $\mathrm{Cu}$, monocrystal $\mathrm{Al}$, ideal-contact $\mathrm{Cu} / \mathrm{Al}$ and diffusion-bonded $\mathrm{Cu} / \mathrm{Al}$ are, respectively, 7.2, 4.9, 3.6 and $3.2 \mathrm{GPa}$. These strength values demonstrate the effectiveness of the diffusion bonding process in creating a bond between the two metals. The strength values here are one order of magnitude higher than those from experiments [26], primarily because the material models contain no initial defects, such as dislocations, voids, grain boundaries and impurities.

\section{Conclusions}

MD simulations of the $\mathrm{Cu} / \mathrm{Al}$ diffusion bonding process and the subsequent tension deformation have been carried out. The primary findings are:

(1) Temperature plays a very important role in the bonding process. When the temperature is lower than $600 \mathrm{~K}$, no obvious diffusion occurs. Above $600 \mathrm{~K}$, higher temperatures yield thicker interfacial layers. The thickness of the interfacial region increases in a stepwise manner when the temperature is lower than $750 \mathrm{~K}$ and increases rapidly and continuously when temperature is higher than $750 \mathrm{~K}$.

(2) When surface roughness is present, the bonding process can be divided into three stages. In the first stage, the rough surface deforms under stress before heating, resulting in an increase in contact area. In the second stage, the surface deforms significantly as temperature increases. Also, interstices disappear and fully intimate contact is achieved in this stage. The last stage entails diffusion of atoms.

(3) The diffusion-bonded $\mathrm{Cu} / \mathrm{Al}$ surface pair obtained under the conditions analyzed demonstrates very good mechanical properties, with a tensile strength of about $88 \%$ of that of the ideal contact $\mathrm{Cu} / \mathrm{Al}$ pair.
The deformation mechanism of diffusion-bonded $\mathrm{Cu} /$ $\mathrm{Al}$ interfaces is not the same as those for single crystal $\mathrm{Cu}$ and $\mathrm{Al}$. The interface between the dissimilar materials blocks the propagation of dislocations from the $\mathrm{Al}$ region into the $\mathrm{Cu}$ region, giving rise to more pronounced strain hardening when compared with the monocrystals.

\section{Acknowledgements}

This research is supported by the National Natural Science Foundation of China through Grant nos. 10372012, 10432050 and 10528205. The computations are performed on the PC clusters of the State Key Laboratory for Scientific and Engineering Computing of the Chinese Academy of Sciences.

\section{References}

[1] Owczarski WA, Paulonis DF. Weld J 1981;62:22.

[2] Guo ZX, Ridley N. Mater Sci Technol 1987;3(11):945.

[3] Fukumoto S, Hirose A, Kobayashi K. Prod Eng 1989;46:374.

[4] Aleman B, Gutierrez I. Trans A 1995;26(2):437.

[5] Aleman B, Guterrez I, Urcola JJ. Scripta Mater 1997;36(5):509.

[6] Askeland DR. The science and engineer of materials. Hong Kong: Van Nostrand Reinhold; 1989.

[7] Yilmaz O, Celik H. J Mater Process Technol 2003;141:67.

[8] Wang A, Ohashi O, Norio Y, et al. J Electron Microsc 2004;53(2): 157.

[9] Weissmann M, Ramfrez R, Kiwi M. Phys Rev B 1992;46:2577.

[10] Chen JK, Frakas D, Reynolds WT. Acta Mater 1997;45:4415.

[11] Cherne FJ, Baskes MS, Schwarz RB. J Non-crystal Solids 2003;317:45.

[12] Heino P. Comput Mater Sci 2001;20:157.

[13] Watanabe T, Tatsummura K, Ohdomari I. Appl Surf Sci 2004;237(1-4):125.

[14] Chen SD, Soh AK, Ke FJ. Scripta Mater 2005;52:1135.

[15] Liu H, Ke FJ, Pan H, et al. Acta Physica Sinica 2007;56(1):407 [in Chinese].

[16] Foiles SM, Baskes MI, Daw MS. Phys Rev B 1986;33(12):7983.

[17] Johnson RA. Phys Rev B 1989;39:12554.

[18] Zhou XW, Wadley HNG, Johnson RA, et al. Acta Mater 2001;49:4005.

[19] Hockney RW. Methods Comput Phys 1970;9:136.

[20] Richmond O, Morrison HL, Devenpeck ML. Int J Mech Sci 1974;16(1):75.

[21] Zuruzi AS, Li H, Dong G. Mater Sci Eng A 1999;270:244.

[22] Derby B, Wallach ER. Metal Sci 1982;16:49.

[23] Derby B, Wallach ER. Metal Sci 1984;18:427.

[24] Elzey DM, Wadley HNG. Acta Metall Mater 1993;41(8):2297.

[25] Xu Z, Liang HY, Wang XX. Acta Mech Solida Sin 2003;24(2): 229.

[26] Shen YF, Lu L, Lu QH, et al. Scripta Mater 2005;52(10):989. 